\title{
Semilunar Coronally Repositioned Flap- the Minimally Invasive Root Coverage Technique: A Report of 3 Cases
}

\author{
Subramony Bhagavatheeswaran, Bhumika Gumber
}

\section{ABSTRACT}

\begin{abstract}
Introduction: Gingival recession (GR) is the location of marginal periodontal tissues apical to the cemento-enamel junction. Treatment of GR can be done by free gingival graft, laterally positioned pedicle flap, coronally displaced flap, and subepithelial connective tissue graft, semilunar coronally repositioned flap (SCRF). The purpose of this case report is to highlight the simplicity of carrying out SCRP procedure and its long-term benefits in case of maxillary gingival recession.
\end{abstract}

Methods: Three systemically healthy patients aged 35-43 years reported with chief complaint of unesthetic appearance of teeth. Following full mouth scaling and root planning, patients were scheduled for root coverage procedure. SCRF was performed under local anaesthesia and postoperative instructions were given. Patients were asked to record VAS pain score and number of analgesics consumed for 3 days and recalled on $3^{\text {rd }}, 10^{\text {th }}$ day, 1 , 3,6 months and 1 year postoperatively.

Results: All patients showed complete root coverage for 1 year postoperatively. VAS score showed mild pain for 3 days postoperatively.

Conclusion: Semilunar coronally advanced flap is an effective, simple and highly acceptable periodontal plastic procedure.

Keywords: Gingival recession, surgical flaps, visual analog scale.
Published Online: January 27, 2022

ISSN: $2684-4443$

DOI : 10.24018/ejdent.2022.3.1.130

\section{S. Bhagavatheeswaran}

Department of Periodontics, Post Graduate Institute of Dental Sciences, Rohtak, Haryana, India.

(e-mail: smb1993@gmail.com)

B. Gumber*

Division of Periodontology, Center for Dental Education and Research, All

India Institute of Medical Sciences, New Delhi, India.

(e-mail:

bhumikagumber13@gmail.com)

*Corresponding Author

\section{INTRODUCTION}

Gingival recession is the location of marginal periodontal tissues apical to the cemento-enamel junction (CEJ).[1] The etiology of gingival recession can be ascribed to excessive or improper tooth brushing or flossing, gingival inflammation, gingival loss secondary to specific diseases such as necrotizing ulcerative periodontitis and herpetic gingivostomatitis, high frenal attachment and iatrogenic causes such as crown preparation.

Surgical therapy is warranted if recession results in unpleasant aesthetics, root caries, or dentinal hypersensitivity [2]-[4]. The goal of periodontal plastic surgery is to maintain or restore a healthy gingival appearance around teeth and coverage of denuded roots. Common surgical techniques aimed at root coverage include free gingival grafts (FGG), laterally positioned pedicle flaps, coronally repositioned flaps (CRF), and subepithelial connective tissue (SECT) grafts. SECT graft has been demonstrated to be more predictable compared to free gingival graft in terms of obtaining root coverage and offers a good color match [5], [6]. However, its disadvantage is multiple surgical sites leading to increased patient morbidity. Coronally repositioned flap has been shown to be a clinically successful periodontal plastic procedure by different authors in terms of the outcome of root coverage [7]-[9]. Since conventional CRF has been associated with shortening of vestibular depth, Sumner and Ward modified the CRP by giving a straight horizontal incision in alveolar mucosa [10], [11]. Reference [2] described semilunar coronally repositioned flap (SCRF) in which semilunar incision followed the curvature of free gingival margin. The purpose of this case report is to highlight the simplicity of carrying out SCRF procedure and its long-term benefits in case of maxillary gingival recession.

\section{CASE REPORT}

Three systemically healthy patients aged 35-43 years reported to the department of periodontics and oral implantology, Post Graduate Institute of Dental Sciences Rohtak, Haryana, India with chief complaint of unaesthetic appearance of teeth. On clinical examination, gingival recession was noted. A thorough clinical examination was carried out (Table-I) and treatment plan formulated. After taking written informed consent, a single sitting full mouth scaling and root planing (SRP) was done. Root coverage surgery was scheduled one month post SRP. Under local anesthesia, a semilunar incision was made using a \#15C blade following the curvature of the free gingival margin and ending $2 \mathrm{~mm}$ apical to the tip of the interdental papilla. A split thickness dissection was done from the incision coronally and connected with intrasulcular incision. The midfacial tissue was repositioned in a coronal direction to the CEJ. The repositioned tissue was held in place using a pressure pack against the tooth with moist gauze for $5 \mathrm{~min}$ and no sutures were placed. Patient was advised to use chlorhexidine 
mouthwash $0.2 \%$ twice daily and take soft diet for 10 days. Analgesic medication (Ibuprofen $600 \mathrm{mg}$ ) was given once immediately post-surgery and the patients were advised to take further doses if required. Patients were asked to record intensity of pain using Visual Analogue Scale (VAS) with values ranging from 0-10 and number of analgesics taken for
3 days post-surgery. Post-surgical healing was evaluated on the $10^{\text {th }}$ day, 1, 3, 6 months and 1 year (Fig. 1-3). In all the patients, healing was uneventful with complete coverage of the recession defect. Oral hygiene instructions were reinforced on the recall visits and SRP performed whenever required.

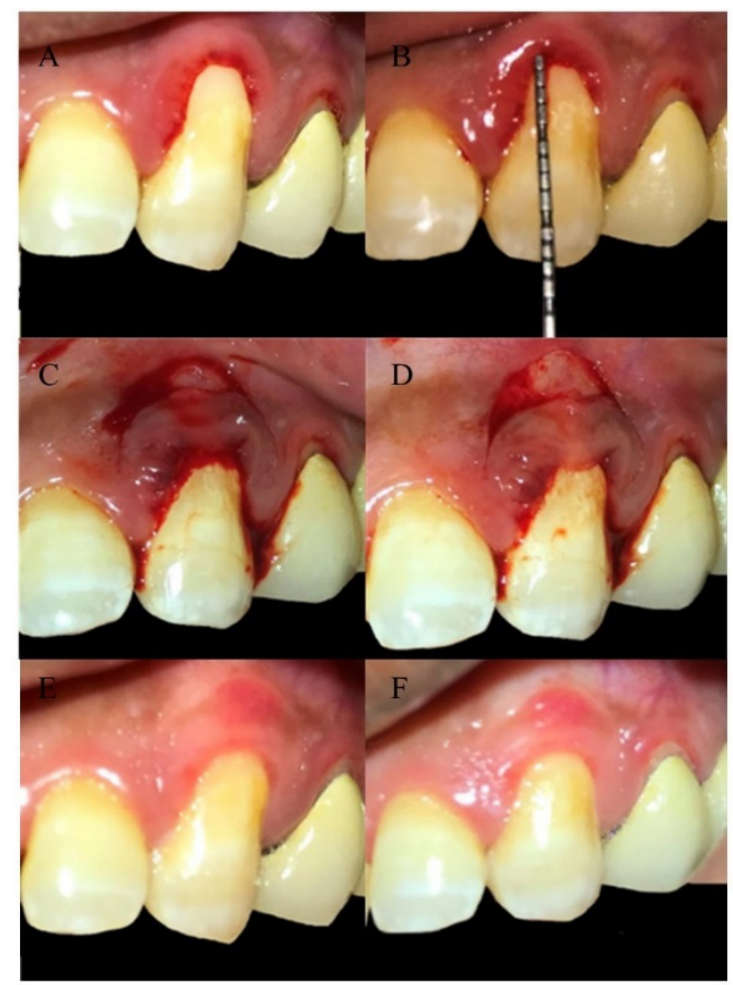

Fig. 1. A. Pre-operative B. Measuring the Recession Depth C\&D. Semilunar incision given, and split thickness flap raised E\&F. 3- and 6-month follow-up.
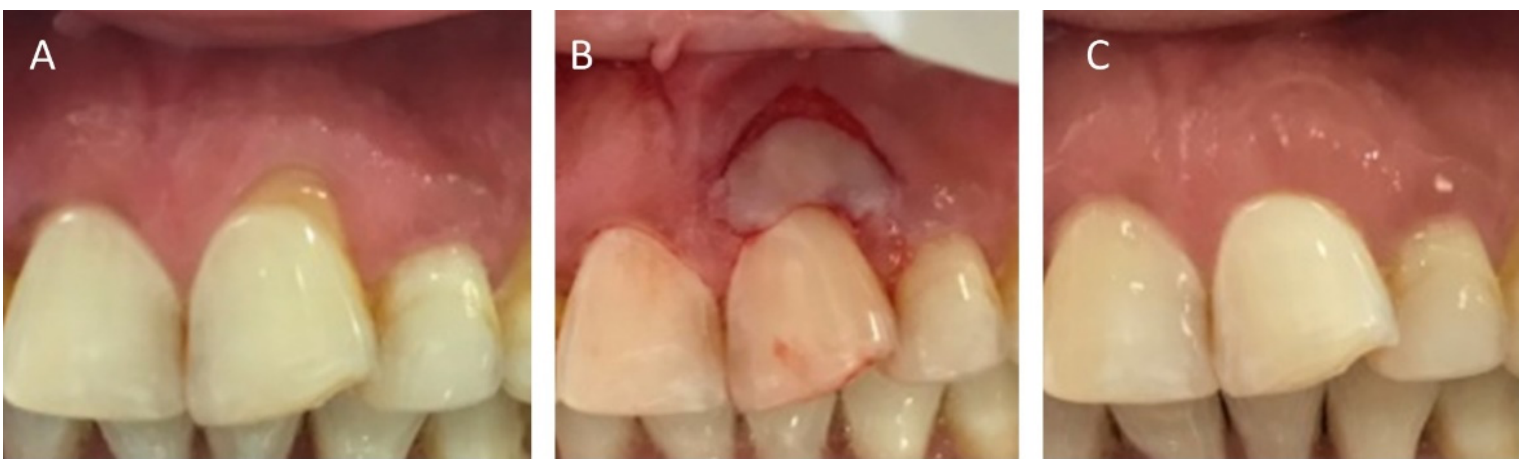

Figure 2. A. Pre-operative B. Intra-operative C. 3-month follow-up.
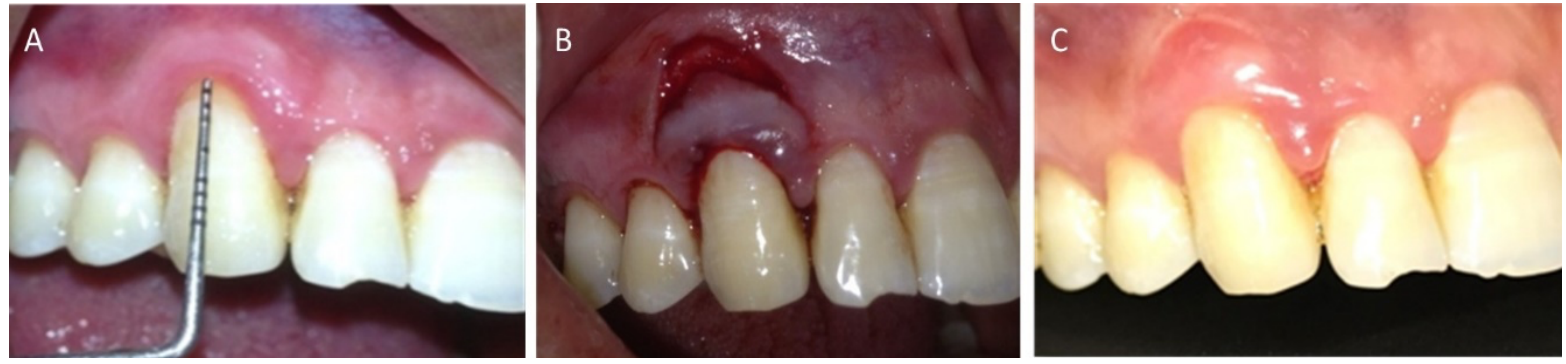

Figure 3. A. Pre-operative B. Intra-operative C. 3-month follow-up. 


\section{Results}

Table I depicts the demographic details of study participants. Root coverage: All patients showed complete root coverage in both RT1 and RT2 recession as shown in
Table I. VAS score and number of analgesics taken: All the patients demonstrated mild pain for 3 days postoperatively and resulted in no analgesic consumption on $3^{\text {rd }}$ day postsurgery as shown in Table II.

TABLE I: DEMOGRAPHIC CHARACTERISTICS AND CLINICAL PARAMETERS OF STUDY PARTICIPANTS

\begin{tabular}{|c|c|c|c|c|c|c|c|c|c|c|}
\hline $\begin{array}{l}\text { S. } \\
\text { No }\end{array}$ & $\begin{array}{c}\text { Age (in } \\
\text { years)/Sex }\end{array}$ & $\begin{array}{l}\text { Tooth } \\
\text { number }\end{array}$ & $\begin{array}{c}\text { Preoperative } \\
\text { recession } \\
\text { grade }^{17}\end{array}$ & $\begin{array}{c}\text { Recession } \\
\text { depth } \\
(\mathrm{mm})\end{array}$ & $\begin{array}{c}\text { Tooth } \\
\text { malpositioning } \\
(\mathrm{Yes} / \mathrm{No})\end{array}$ & $\begin{array}{c}\text { Gingival } \\
\text { Phenotype }\end{array}$ & $\begin{array}{c}\text { Associated } \\
\text { symptoms } \\
\text { (if any) }\end{array}$ & $\begin{array}{c}\% \\
\text { Coverage } \\
\text { obtained }\end{array}$ & $\begin{array}{l}\text { Complications } \\
\text { (if any) }\end{array}$ & $\begin{array}{c}\text { Follow } \\
\text { up }\end{array}$ \\
\hline 1 & 40/Female & 11 & RT 2 & 2 & No & Thick & Hypersensitivity & 100 & Nil & 1 year \\
\hline 2 & $35 /$ Female & 9 & RT 1 & 2 & Yes & Thick & Nil & 100 & Nil & 1 year \\
\hline 3 & 43/Male & 6 & RT 2 & 1 & No & Thick & Nil & 100 & Nil & 1 year \\
\hline
\end{tabular}

TABLE II: VISUAL ANALOGUE SCALE (VAS) SCORE AND NUMBER OF ANALGESICS TAKEN IN THE FIRST 3 DAYS AFTER SURGERY

\begin{tabular}{ccccccc}
\hline \hline & \multicolumn{3}{c}{ Pain intensity (VAS score) } & \multicolumn{3}{c}{ Number of analgesics taken } \\
\hline \hline S. No & Day 1 & Day 2 & Day 3 & Day 1 & Day 2 & Day 3 \\
\hline 1 & 3 & 1 & 1 & 1 & 1 & 0 \\
2 & 2 & 1 & 1 & 1 & 0 & 0 \\
3 & 2 & 1 & 1 & 1 & 0 & 0 \\
\hline \hline
\end{tabular}

\section{Discussion}

In the era of cosmetic renaissance, patients are highly conscious about aesthetics, predominantly in the oro-facial region. It is the responsibility of the treating dentist to provide the patients with the simplest, cost effective and predictable treatment. Although there are many modalities for the treatment of gingival recession including the use of connective tissue grafts, acellular dermal graft, free gingival grafts, SCRF is probably the simplest, least invasive, onestage periodontal plastic surgical procedure with maximum patient acceptance. This technique has more precedence that it does not involve the adjacent papillae, there is no shortening of the vestibule, minimal flap tension and requires no sutures [2].

Also, in comparison with SECT graft, which is the gold standard in root coverage procedures, [12] SCRF is less invasive, has faster post-healing, involves fewer surgical sites with minimal patient morbidity [13]-[16]. These characteristics makes it the most minimally invasive root coverage technique.

The primary outcome measure of root coverage procedures is determined by the amount of recession coverage, assessed by measuring the distance between the cementoenamel junction and the gingival margin [12]. Studies have shown no statistically significant difference in terms of root coverage and success rate between semilunar flap and connective tissue graft [16]. In the present case series, complete root coverage was attained in both RT1 and RT2 recession types which remained stable throughout the follow-up period of one year.

The VAS pain assessment showed minimal discomfort for all the patients which resulted in negligible consumption of analgesics postoperatively. There was no postoperative complication.

One of the possible limitations of SCRF is that it can be only employed in the coverage of shallow gingival recessions and is feasible in teeth with thick gingival biotype.

\section{CONCLUSIONS}

Semilunar coronally advanced flap is an effective, simple and highly acceptable periodontal plastic procedure showing satisfactory outcome in terms of root coverage, patient acceptance for treatment of gingival recessions.

\section{FUNDING}

There are no sources of funding.

\section{CONFLICT OF INTEREST}

Authors declare that they do not have any conflict of interest.

\section{REFERENCES}

[1] American Academy of Periodontology. Glossary of periodontal terms. $4^{\text {th }}$ ed. Chicago: The American academy of Periodontology. 2001.

[2] Tarnow DP. Semilunar coronally repositioned flap. J Clin Periodontol. 1986; 13: 182-5.

[3] Glover ME. Periodontal plastic and reconstructive surgery. Periodontics: Medicine, Surgery and Implants. 2004.

[4] Wennstrom JL. Mucogingival therapy. Ann Periodontol. 1996; 1: 671701.

[5] Sbordone L, Ramaglia L, Spagnuolo G, De Luca M. A comparative study of free gingival and subepithelial connective tissue grafts. Periodontal Case Rep. 1988; 10: 8-12.

[6] Paolantonio M, Di Murro C, Cattabriga A, Cattabriga M. Subpedicle connective tissue graft versus free gingival graft in the coverage of exposed root surfaces. A 5-year clinical study. J Clin Periodontol. 1997; 24: 51-56.

[7] Kalmi J, Moscor M, Goronov. Z. The solution of the aesthetic problem in the treatment of periodontal disease of anterior teeth: Gingivoplastic operation. Paradentologie. 1949; 3: 53.

[8] Nordenram A, Landt H. Evaluation of a surgical technique in the periodontal treatment of maxillary anterior teeth. Acta Odontologica Scandinavica. 1969; 11: 283.

[9] Harvey PM. Surgical reconstruction of the gingiva. Part II, procedure. New Zealand Dental Journal. 1970; 66: 42.

[10] Sumner CF. Surgical repair of recession on the maxillary cuspid. Incisally repositioning the gingival tissues. Journal of Periodontologv. 1969; 40: 119.

[11] Ward H, Simering M. Manual of clinical periodonties. 1973: 81-2. 
[12] Bouchard P, Malet J, Borghetti A. Decision-making in aesthetics: Root coverage revisited. Periodontol. 2001; 27: 97-120.

[13] Casati MZ, Nociti FH Jr, Sallum EA, Nogueira GR, Sallum AW. Treatment of gingival recessions by semilunar coronally positioned flap. Rev Assoc Paul Cir Dent. 2001; 55: 169-172.

[14] Nasr HF, Nasr AMS. The semilunar flap technique for root coverage. Atlas Oral Maxillofac Surg Clin North Am. 1999; 7: 29-37.
[15] Desensitization of exposed root surfaces using a semilunar coronally positioned flap. Gen Dent. 2000; 48: 68-71.

[16] Bittencourt S, Ribeiro Edel P, Sallum EA, Sallum AW, Nociti FH, Casati MZ. Semilunar coronally positioned flap or subepithelial connective graft for the treatment of gingival recession: A 30-month follow-up study. J Periodontol. 2009; 80: 1076-82. 